\title{
KUDZU, PUERARIA MONTANA (LOUR.) MERR. ABUNDANCE AND DISTRIBUTION IN OKLAHOMA
}

\author{
Marli Claytor \\ Karen R. Hickman \\ Natural Resource Ecology and Management \\ Oklahoma State University \\ 008C Ag Hall \\ Stillwater, OK 74078 \\ karen.hickman@okstate.edu
}

Key words: invasion, invasive species, mapping, federal noxious weed

\begin{abstract}
Invasive species are a growing problem in the United States, and kudzu (Pueraria montana) (Lour.) Merr. is one of the most well documented invaders of southeastern states. Documenting the invasion of kudzu in Oklahoma, however, has not been a targeted focus in previous studies; thus, maps of its occurrence differ among sources. Our primary objective was to locate and confirm the presence of kudzu throughout Oklahoma. Specifically, we attempted to confirm previously recorded populations of kudzu and estimate the extent of the invasion at those sites. In addition, we wanted to locate stands of kudzu within Oklahoma that had not been recorded and to assess the extent of invasion. A survey was sent to state and county officials to acquire information on locations and general knowledge of kudzu. Points of occurrence and estimated extent of invasion in hectares were then placed in ArcMap programming to create a consolidated map of kudzu. Samples were collected, pressed, and placed in the University of Oklahoma's Bebb Herbarium (OKL). We determined the majority of kudzu locations are in the southeastern portion of the state and total a minimum of 32.4 hectares. Results of the survey indicated half of the respondents polled were unaware of kudzu's presence in the state.

\section{INTRODUCTION}

Invasive species are a growing concern in the United States, as well as across the globe. There are approximately 17,000 native species of vascular plants in the U. S., compared to a continually increasing estimate of 6,000 nonnative species (Forseth and Innis 2004). Invasive species can be detrimental to the environments they occupy and cause major ecosystem changes (Mitich 2000). Kudzu, Pueraria montana (Lour.) Merr. (Fabaceae) is an introduced, leguminous vine which causes major changes in areas in which it invades. Kudzu is listed as one of the world's 100 worst

invasive species of all time (Sage et al. 2009). First introduced at the 1876 Centennial Exposition in Pennsylvania, kudzu has since made a lasting impact on the southeastern U. S. (Brown 2010). Upon introduction, the vine was sold to the public to aid with soil erosion control and as forage for livestock; additionally, the Soil Conservation Service (currently Natural Resources Conservation Service) and other national agencies encouraged the planting of kudzu (Forseth and Innis 2004). Eventually, evidence indicated that the vine overtopped mature trees, took over native plant dominated areas, buildings, and disturbed areas, and became a financial burden to those who
\end{abstract}


tried to control and eradicate the invader. Kudzu has been found to alter a landscape abruptly as it can grow up to $30 \mathrm{~cm}$ a day and between 10 to $30 \mathrm{~m}$ in one growing season (Mitich 2000). Additionally, kudzu fixes nitrogen and releases isoprene into the environment, which can create pollution in the atmosphere, further reducing environmental value (Hickman et al. 2010).

Kudzu is one of the worst invasive species in the U.S. and is continuing its spread across the country (Fig. 1). It has been estimated that the vine covers 2.83 million hectares in the Southeast, in 1955 was declared a weed by the U.S.
Department of Agriculture (Alderman 1998) and declared a federal noxious weed in 1999 (Mitich 2000). Kudzu has a wide climatic range which facilitates its ability to continue spreading northward (Mitich 2000). It has been suggested that kudzu is limited in its range by annual rainfall, which needs to be a minimum of $100 \mathrm{~cm}$ a year (Mitich 2000). The vine is also considered to be limited in its distribution by lack of hardiness; however, it has exceeded many expert predictions in range expansion (Mitich 2000). This area includes Oklahoma, which was once believed to be unsuitable habitat for kudzu (Mitich 2000).

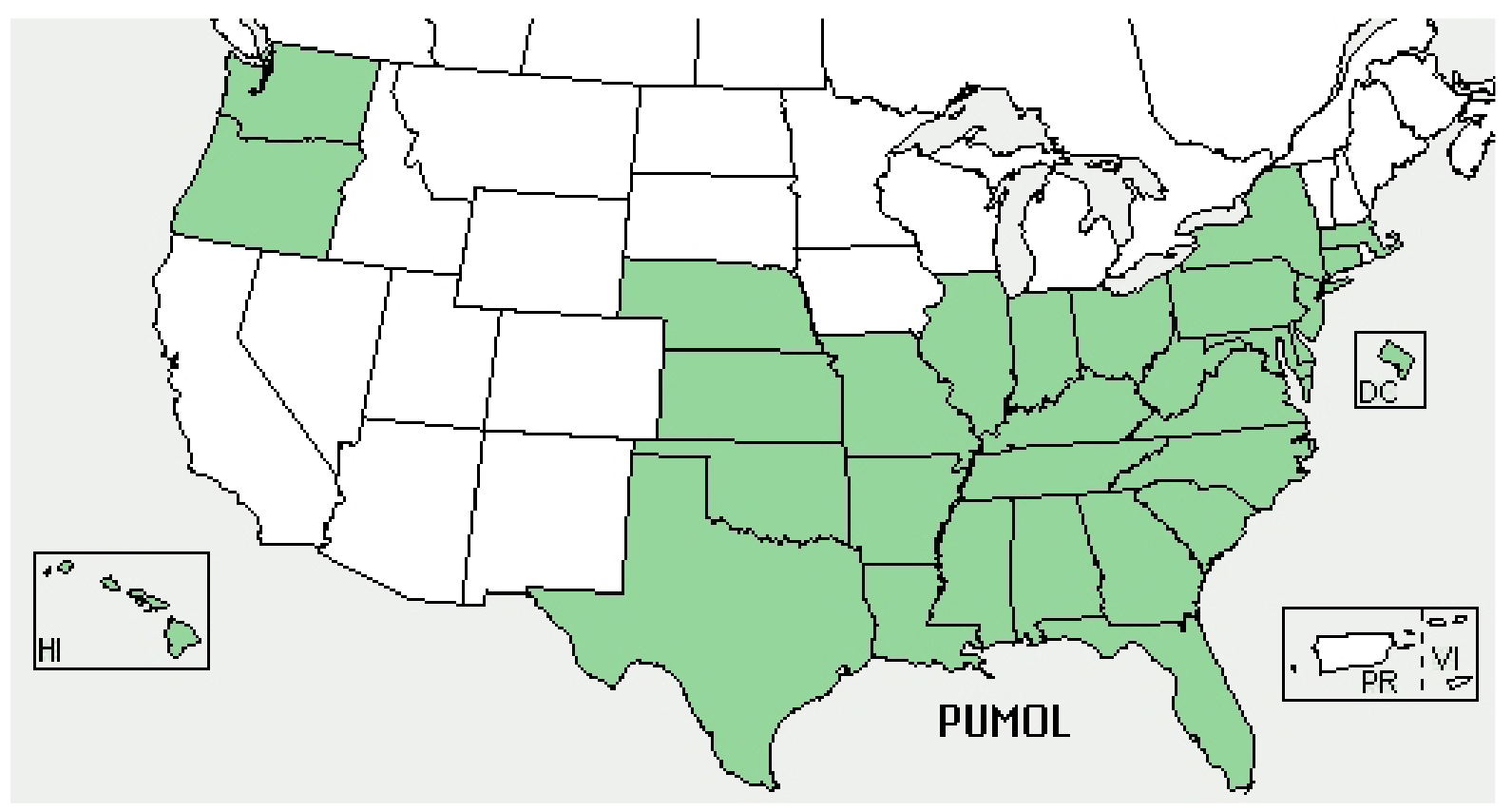

Figure 1 Distribution map of kudzu across the United States, in the USDA PLANTS database http://plants.usda.gov/core/profile? symbol=PUMO

Kudzu is present in Oklahoma but has not been the focus of a targeted survey in the state. Because of the variability in data, maps illustrating the distribution of kudzu are inconsistent among sources (e.g., state and national agencies). Thus, a need for an updated map has arisen for future management of the species. For instance, the Oklahoma Vascular Plant Database map, whose data are based on herbarium records, indicates 22 counties with kudzu (Fig. 2), while a map from Early Detection and Distribution Mapping Systems (EDDMapS) includes 12 counties 
(Oklahoma Vascular Plant Database 2014; EDDMaps 2014). While some of the occurrences overlap, there are some inconsistencies. Importantly, none of these maps are based on a compilation of reliable field observations and specimens that have been critically examined by experts. Thus, we attempted to confirm previously known locations, obtain information about new sightings, and collect specimens for confirmation. A survey was utilized to cover Oklahoma as a whole and to gather as much information as possible about the plant from knowledgeable persons primarily within the Oklahoma State University Extension Service. Surveys have been found to be a useful tool when other forms of data sources or collection methods are not adequate, and in this case it was not practical to reach as many people through other methods (Innovation Insights 2006). Survey reports were then confirmed by groundtruthing and utilized to create a detailed map of kudzu locations and the extent of invasion at each site.

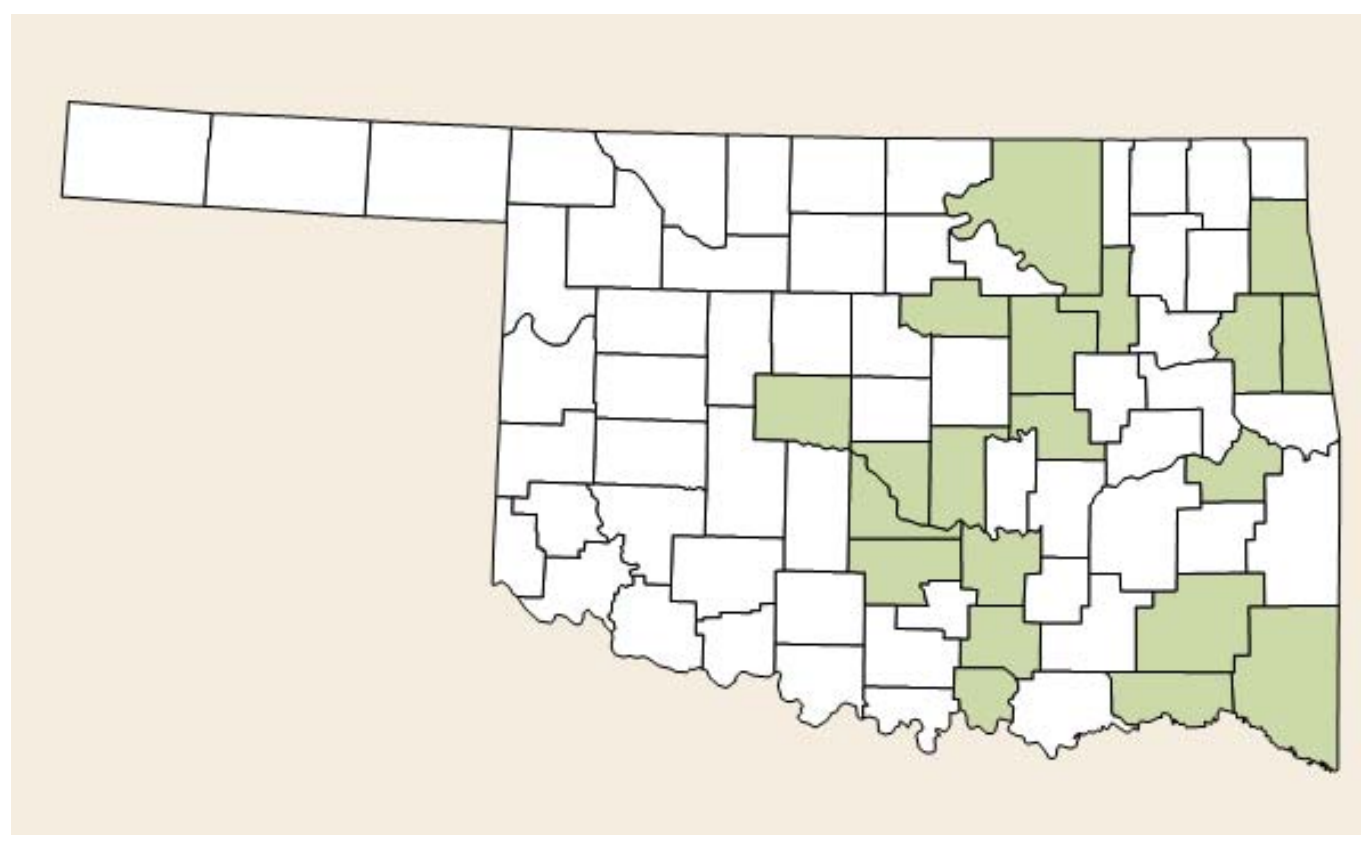

Figure 2 Oklahoma Vascular Plant Database map of kudzu occurrence by county http://www.oklahomaplantdatabase.org

\section{METHODS}

Kudzu location, extent of invasion, and date of record were obtained from available records, which included the OVPD records of herbarium specimens, information collected by the Oklahoma Invasive Plant Council (OkIPC; K. Hickman, unpublished), directed contact with botanists in the state, and through a survey sent to OSU Extension personnel, land managers known to have experience with kudzu, Oklahoma Department of Wildlife Conservation employees, and the OkIPC. The survey provided the majority of data collected.

A link to the kudzu survey, which was created through Survey Monkey (www.surveymonkey.com), was sent out through email. Five questions were asked regarding the respondent's knowledge of kudzu and its presence in Oklahoma. 
Questions asked in the survey included:

1) What county of Oklahoma are you currently working or residing in? 2) Have you seen or heard of Kudzu inhabiting land in Oklahoma? 3) If so, please provide the locations of the kudzu sightings. 4) In acres, how large of an area would you estimate that the infestation is at each site? 5) Please provide contact information for verification and/or additional inquiries. Approximately two hundred invitations were emailed to OSU County Extension offices, Oklahoma Department of Wildlife Conservation, Oklahoma Department of Transportation, and the Oklahoma Invasive Plant Council members. These agencies and organizations were chosen based on previous experience we have had with them concerning invasive species and the ability to send mass emails to the group. Also, individuals were included who had knowledge of Oklahoma vegetation and ecosystems, or who dealt with invasive species frequently.

We used ArcGIS ArcMap v. 10.1 (Esri, Redlands, CA) software to create distribution maps. A state overview illustrating counties with kudzu present was created, along with more detailed maps of the counties displaying extent of the invasion of kudzu. Estimates of the extent invaded were made on sites (19), approximated from GoogleEarth imagery (4), or reported in the surveys (5). Points were added to the map for individual stands of kudzu across Oklahoma, illustrating area invaded for each location within the county. For our map, we included sites that were confirmed to have kudzu; we did not include locations of kudzu that we visited and confirmed kudzu was not present. Mapped points (Table 1) only include confirmed locations of kudzu, but not sites in OVPD that were not confirmed via a visit or sites visited where no plants were found.

Samples of kudzu were collected from all confirmed sites visited (16) to create herbarium voucher specimens. We traveled to some, but not all of the locations, due to time constraints of the project (see Table 1). Sites chosen to visit were those with larger infestations reported or those reported in the survey. Samples of individual plants were cut in sections including leaves, flowers, and pods (if available, as samples were taken throughout the project year). Specimens were deposited at the University of Oklahoma's Bebb Herbarium (OKL).

\section{RESULTS}

The survey received 52 responses from the approximately 200 emails sent, which indicates a return rate of close to $25 \%$. Of those, over $50 \%$ (28) respondents had knowledge of kudzu in Oklahoma, while $46 \%$ (24) reported having not seen or heard of the vine's encroachment within the state. Of those surveyed, 17 provided locations, and 10 estimated dimensions of the area invaded of kudzu. Of those reported, 9 locations were new, previously unrecorded sites of kudzu.

Maps (Figs. 3, 4) were created using data from the survey and previously known locations (confirmed by groundtruthing) of kudzu (see Table 1). If kudzu was confirmed as absent from a site, then it was removed from the map. A gray scale was utilized to illustrate the extent of invasion of kudzu in each county. Figure 3 presents specific locations of kudzu in the state along with their corresponding extent of invasion, while Figure 4 illustrates presence and extent by county. Based on our results, at least 32.4 hectares of land are invaded by kudzu in Oklahoma across 28 sites. 
Table 1 Locations of kudzu identified from previous documentation (Oklahoma Vascular Plants Database), survey results, or on-site discoveries. Kudzu was confirmed present or absent via site visits or previous documentation. Estimates of the extent of kudzu invasion were obtained during on-site visits using GPS or GoogleEarth imagery.

\begin{tabular}{|c|c|c|c|c|c|}
\hline Site Name & Longitude & Latitude & $\begin{array}{c}\text { Source of } \\
\text { Location Data }\end{array}$ & $\begin{array}{l}\text { Source of } \\
\text { Extent of } \\
\text { Invasion }\end{array}$ & $\begin{array}{c}\text { Status of } \\
\text { Kudzu on } \\
\text { Site }\end{array}$ \\
\hline Idabel & -94.709 & 33.896 & $\begin{array}{l}\text { Discovered by } \\
\text { Marli Claytor }\end{array}$ & $\begin{array}{l}\text { Google Earth to } \\
\text { estimate coverage }\end{array}$ & $\begin{array}{l}\text { Confirmed } \\
\text { present }\end{array}$ \\
\hline Claremore & -95.599 & 36.299 & From survey & Site Visit & $\begin{array}{l}\text { Confirmed } \\
\text { present }\end{array}$ \\
\hline Antlers & -95.637 & 34.233 & $\begin{array}{l}\text { Discovered by } \\
\text { Marli Claytor }\end{array}$ & $\begin{array}{l}\text { Google Earth to } \\
\text { estimate coverage }\end{array}$ & $\begin{array}{l}\text { Confirmed } \\
\text { present }\end{array}$ \\
\hline $\begin{array}{l}\text { P St. \& Springdale Rd. } \\
\text {, Ardmore }\end{array}$ & -97.108 & 34.159 & $\begin{array}{l}\text { Previous } \\
\text { documentation }\end{array}$ & Site visit & $\begin{array}{l}\text { Confirmed } \\
\text { present }\end{array}$ \\
\hline Marsden Rd. Love Co. & -97.195 & 34.070 & Site visit & Site visit & $\begin{array}{l}\text { Confirmed } \\
\text { present }\end{array}$ \\
\hline $\begin{array}{l}\text { Tater Hill Rd. } \\
\text { Ardmore }\end{array}$ & -97.008 & 34.144 & $\begin{array}{l}\text { Previous } \\
\text { documentation }\end{array}$ & Site visit & $\begin{array}{l}\text { Confirmed } \\
\text { present }\end{array}$ \\
\hline Shawnee & -96.962 & 35.333 & $\begin{array}{l}\text { Previous } \\
\text { documentation } \\
\text { / survey }\end{array}$ & $\begin{array}{l}\text { Google Earth to } \\
\text { estimate coverage }\end{array}$ & $\begin{array}{l}\text { Confirmed } \\
\text { present }\end{array}$ \\
\hline Haskell & -95.611 & 35.754 & From survey & $\begin{array}{l}\text { Google Earth to } \\
\text { estimate coverage }\end{array}$ & $\begin{array}{l}\text { Confirmed } \\
\text { present }\end{array}$ \\
\hline Eufaula & -95.339 & 35.281 & $\begin{array}{l}\text { Previous } \\
\text { documentation }\end{array}$ & Site visit & $\begin{array}{l}\text { Confirmed } \\
\text { present }\end{array}$ \\
\hline Cleveland County & -97.164 & 35.233 & $\begin{array}{l}\text { Previous } \\
\text { documentation } \\
\text { / survey }\end{array}$ & Site visit & $\begin{array}{l}\text { Confirmed } \\
\text { present }\end{array}$ \\
\hline Dickson & -96.928 & 34.188 & From survey & From survey & Inconclusive \\
\hline Red River & -95.500 & 33.877 & $\begin{array}{l}\text { Previous } \\
\text { documentation }\end{array}$ & Unavailable & Inconclusive \\
\hline
\end{tabular}


Untitled Placemark- $\quad$-95.226

Hulbert

Shoals

North Eufuala

$-95.387$

Norman

$-97.156$

Okemah

$-97.399$

Washita River

$-97.510$

Tributary

Fittstown

$-96.635$

Durant

$-96.410$

Duncan

$-97.986$

Stillwater

$-97.063$

Osage

$-96.304$

Osage

$-96.282$

Adair

Caddo

$-98.324$

Marshall

$-96.685$

Pontotoc

$-96.634$
36.246

36.113

36.242

35.869

33.968

35.391

35.232

35.430

34.779

34.618

34.056

34.594

Previous

documentation

Previous

documentation

From survey

From survey

From survey

35.464

34.148

34.579
Site visit

Confirmed present

Inconclusive

Confirmed present

Confirmed present

Confirmed present

Confirmed present

Confirmed present

Confirmed present

Confirmed present

Confirmed present

Confirmed present

Confirmed present

Inconclusive

Confirmed absent

Confirmed absent

Confirmed absent 


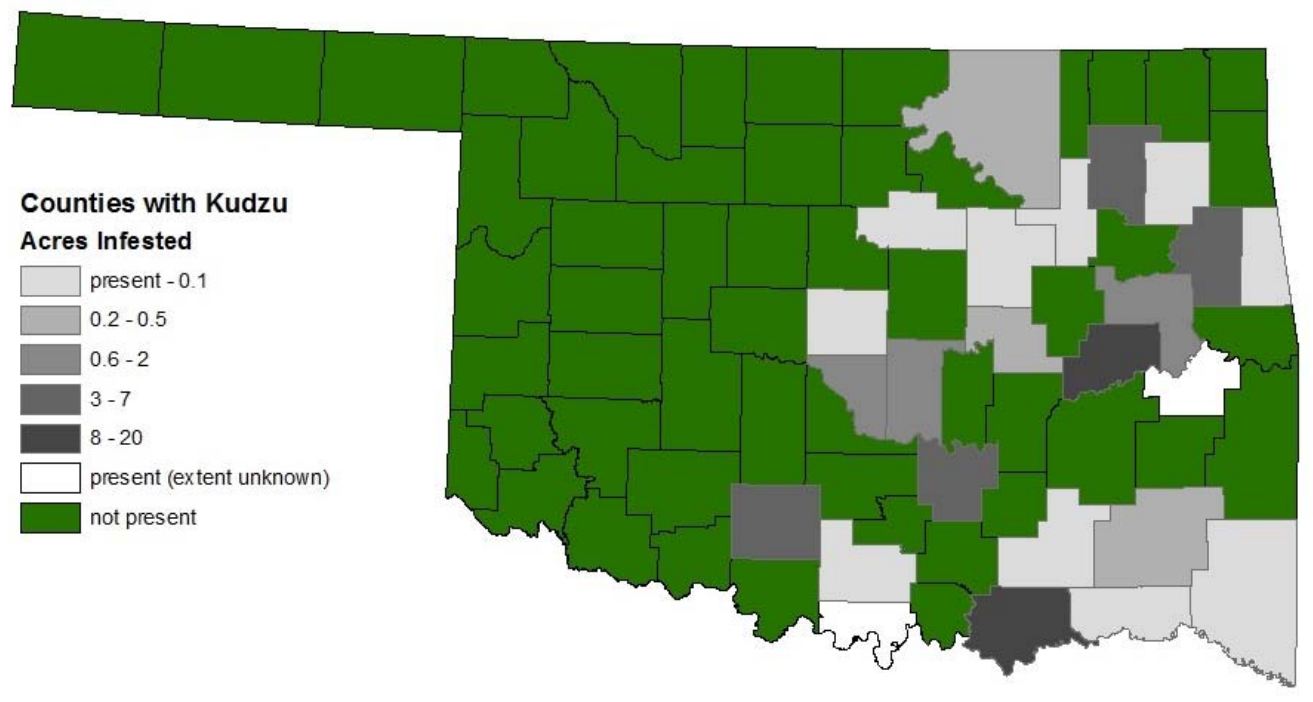

Figure 3 Distribution map of counties with confirmed kudzu invasion, showing acres invaded. Acres represent total acres for all sites within each county. Map created using ArcMap.

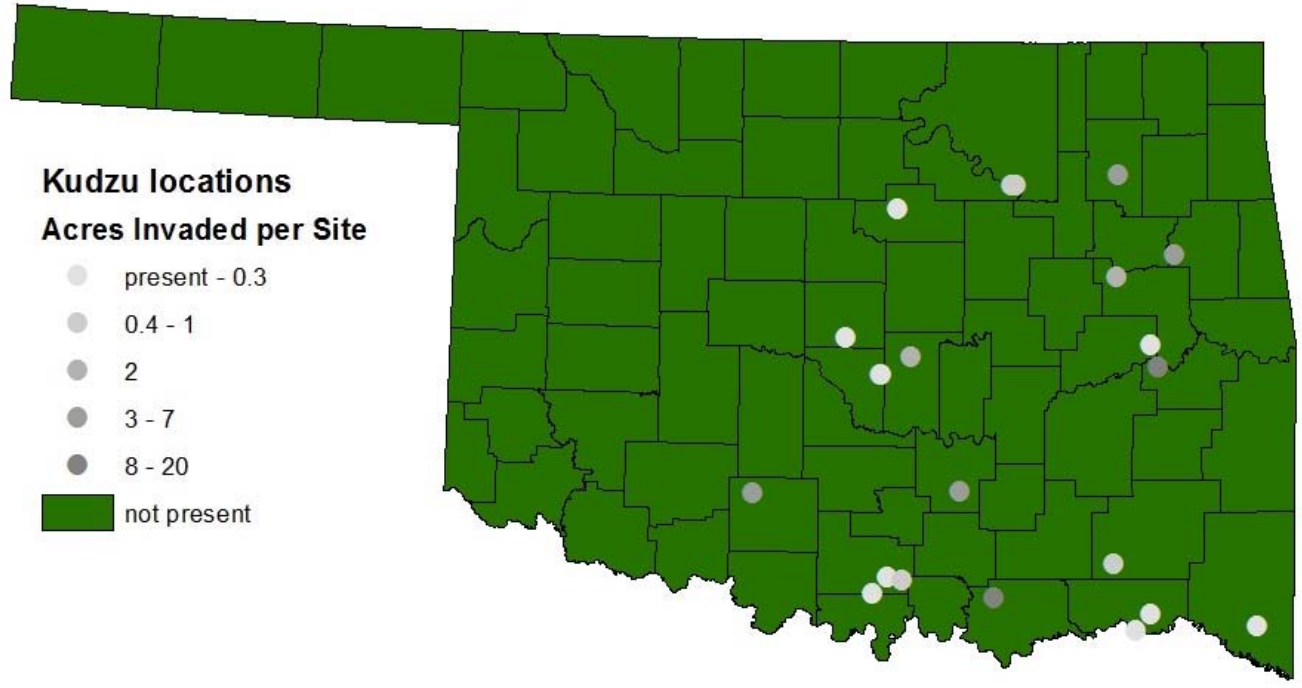

Figure 4 Locations of kudzu across the state of Oklahoma, featuring area invaded for each site. Map was created using ArcMap programming with data from the survey. 


\section{DISCUSSION}

The survey was successful in acquiring important information on kudzu throughout the state. Nearly half of the respondents had no knowledge of kudzu being present in the state, which indicates very little familiarity with the vine even from knowledgeable professionals. Close to 30\% of all sightings reported were new locations in the state. This prompts the question: if we had sent out more surveys, how many more new locations would have been documented?

The new distribution map aids in assessing current and future invasion of kudzu. In comparison to the OVPD, our map includes 22 counties reported while the other has only 20; additionally, not all OVPD counties are included in the new map as some reports could not be confirmed or old populations were found to no longer exist as determined through our site visits (see Figs. 2, 3). It can be observed that kudzu currently exists primarily in the eastern portion of the state. Climatic restrictions are most likely limiting the range of kudzu (Jarnevich and Stohlgren 2009. Once kudzu has invaded an ecosystem it is very difficult to eradicate, further facilitating its spread across Oklahoma. It is likely that kudzu will continue not only its coverage north, but also invade more hectares where stands currently persist (Jarnevich and Stohlgren 2009).

Currently there are at least 32.4 hectares invaded with kudzu in Oklahoma, which is extremely small in comparison to the total seven million hectares invaded in the United States (Eskridge and Alderman 2010). This does not mean we can ignore the problem, but presents our state with an opportunity to stop a problem while we can. If our state began an Early Detection and Rapid Response (EDRR) program for kudzu, it would be possible to limit the future spread of the vine and keep our state and economy safe from the detriment of invasion. EDRR programs work to develop a system of effectively addressing issues of invasive species through the steps of: early detection and reporting of new plants, identification and collection of specimens, verification of new plant records, archival of new records where appropriate, rapid assessment of new records, and rapid response to new records determined to be invasive (Westbrooks 2004). To stop this problem now would save the state financially in the long run. More studies need to be conducted on kudzu, and there is a current study on viability of kudzu seeds in Oklahoma (Zoeller and Hickman, unpublished). This study will be crucial in estimating to what extremes kudzu can further invade Oklahoma.

Education for the state needs to occur to stop the further expansion of kudzu. The creation of our updated map will aid in educating citizens on where the vine resides and if they should be on alert for presence in their area. To inform the public, the first step will be to train county and state officials to properly identify kudzu and instruct citizens on how to handle the issue. Kudzu has caused major damage in the southeastern United States, but this destruction can be reduced through proper education and effectively implementing an EDRR program.

\section{ACKNOWLEDGEMENTS}

We would like to thank those who participated in the survey or contributed a location. Thanks to Oklahoma State University Natural Resource Ecology and Management Department and also the Oklahoma State University Honor's College. Finally, we would like to thank the others who helped complete this project: Aaron Cromer, Dwayne Elmore, Gail Wilson, and Mark Gregory. 


\section{LITERATURE CITED}

Alderman, D.H. 1998. The changing south: A vine for postmodern times: An update on kudzu at the close of the twentieth century. Southeastern Geographer 38:167-179.

Durisin, M. 2014. Kudzu that ate U. S. South heads North as climate changes. Bloomberg Business. http://www.bloomberg.com/news/arti cles/2014-07-25/kudzu-that-ate-u-ssouth-heads-north-as-climate-changes (8 August 2015).

Early Detection \& Distribution Mapping Systems (EDDMapS). 2014. Kudzu. http://www.eddmaps.org/distribution/ usstate.cfm?sub $=2425$ (10 October 2014).

Eskridge, A.E. and D.H. Alderman. 2010. Alien invaders, plant thugs, and the southern curse: framing kudzu as environmental other through discourses of fear. Southeastern Geographer 50:110_ 129.

Forseth, I.N. and A.F. Innis. 2004. Kudzu (Pueraria montana): History, physiology, and ecology combine to make a major ecosystem threat. Critical Reviews in Plant Sciences 23:401-413.

Hickman, J.E., S. Wu, L.J. Mickley, and M.T. Lerdau. 2010. Kudzu (Pueraria montana) invasion doubles emissions of nitric oxide and increases ozone pollution. Proceedings of the National Academy of Sciences, USA 107:1011510119.
Innovation Insights. 2006. Using Surveys for Data Collection in Continuous Improvement. http://www.opia.psu.edu/sites/default/ files/insights014.pdf (7 August 2014).

Jarnevich, C. and T. Stohlgreen. 2009. Near term climate projections for invasive species distributions. Biological Invasions 11:1373-1379.

Mitich, L. 2000. Kudzu [Pueraria lobata (Willd.) Ohwi]. Weed Technology 14:231235.

Oklahoma Vascular Plant Database. 2014. Distribution map of Pueraria montana (kudzu). http://www.oklahomaplantdatabase.org (29 November 2014).

Sage, R.F., H.A. Coiner, D.A. Way, G.B. Runion, S.A. Prior, H.A. Torbert, R. Sicher, and L. Ziska. 2009. Kudzu [Pueraria montana (Lour.) Merr. Variety lobata]: A new source of carbohydrate for bioethanol production. Biomass and Bioenergy 33:57-61.

USDA. NRCS. 2014. The PLANTS Database. Greensboro (NC): National Plant Data Team. http://plants.usda.gov/core/profile?sy mbol=PUMO (17 Oct 2014).

Waldron, G.E. and B.M.H. Larson. 2012. Kudzu vine, Pueraria montana, adventive in southern Ontario. The Canadian FieldNaturalist 126:31-33.

Westbrooks, R.G. 2004. New approaches for early detection and rapid response to invasive plants in the United States. Weed Technology 18:1468-1471. 